\title{
KAJIAN KUAT TEKAN UNIAKSIAL BETON MEMADAT SENDIRI DENGAN KADAR FLY ASH $50 \%$
}

\author{
Agus Setiya Budi ${ }^{1)}$, Senot Sangadji ${ }^{2}$, dan Ridlo Dwi Kurniawan ${ }^{3)}$ \\ 1),2)Pengajar Prodi Teknik Sipil, Fakultas Teknik, Universitas Sebelas Maret \\ ${ }^{3}$ Mahasiswa Prodi Teknik Sipil, Fakultas Teknik, Universitas Sebelas Maret \\ Jl. Ir. Sutami 36A, Kentingan Surakarta 57126; Telp 0271-634524 \\ Email: ridlokurniawan@student.uns.ac.id
}

\begin{abstract}
Self Compacting Concrete (SCC) is an innovation where the concrete can flow by itself without vibrating or human power. SCC concrete uses smaller aggregates than conventional concrete so it is able to flow through the reinforcement. The SCC concrete innovation will be combined with the bigh-grade of fly-ash. This innovation is known as High Volume Fly Ash - Self Compacting Concrete (HVFA-SCC). Fly ash is waste from burning coal at the PLTU which contains high levels of pozzolanic compounds in the form of silica and alumina, so it can be used as a substitute for cement material. In this study, the content of fly ash used was 50\% of the total volume of cement. The purpose of this study is to analyze the effect of using fly ash content of 50\% as cement substitute in SCC concrete. The spesiments used is a cylinder form with $30 \mathrm{~cm} \times 15 \mathrm{~cm}$. The results of this study indicate that the 50\% content of HVFA-SCC produces fresh concrete which has a good level of compactness and can be applied in the manufacture of concrete mix designs. The value of the compressive strength of each specimen is as follows, HVFA.50.A $44.1390 \mathrm{MPa}$; HVFA.50.B = 32,8200 MPa.
\end{abstract}

Keywords: Compressive strength, Fly ash, High volume fly ash, Self compacting concrete.

\begin{abstract}
Abstrak
Self-Compacting Concrete (SCC) merupakan salah satu bentuk inovasi beton dimana beton tersebut dapat mengalir dengan berat sendirinya tanpa bantuan alat penggetar ataupun tenaga manusia. Beton SCC menggunakan agregat yang lebih kecil daripada beton konvensional sehingga mampu mengalir melewati tulangan dengan jarak yang rapat. Inovasi beton SCC tersebut akan dikombinasikan dengan pemakaian fly ash kadar tinggi. Inovasi tersebut dikenal dengan sebutan High Volume Fly Ash - Self Compacting Concrete (HVFA-SCC). Fly ash merupakan limbah hasil pembakaran batu bara pada PLTU yang mengandung senyawa pozzolan berupa silika dan alumina yang cukup tinggi, sehingga dapat dimanfaatkan sebagai material pengganti semen. Pada penelitian ini, kadar fly ash yang digunakan adalah 50\% dari total volume semen. Tujuan dari penelitian ini adalah untuk menganalisis pengaruh penggunaan fly ash kadar 50\% sebagai material pengganti semen pada beton SCC. Benda uji yang digunakan berbentuk silinder ukuran $30 \mathrm{~cm} \times 15 \mathrm{~cm}$. Hasil penelitian ini mengindikasikan bahwa HVFA-SCC kadar $50 \%$ menghasilkan beton segar yang memiliki tingkat kelecakan yang baik dan dapat diaplikasikan pada pembuatan rancang campur beton. Nilai dari hasil kuat tekan setiap benda uji sebagai berikut, HVFA.50.A = 44,1390 MPa; HVFA.50.B = 32,8200 $\mathrm{MPa}$.
\end{abstract}

Kata Kunci : Fly ash, High volume fly ash, Kuat tekan, Self-compacting concrete.

\section{PENDAHULUAN}

Produksi semen tahun 2018 mencapai 534 juta ton atau menyumbang 7\% dari keseluruhan emisi karbondioksida yang ada di bumi (BP Energy Outlook). Oleh karena itu dibutuhkan inovasi yang mampu mengatasi permasalahan tersebut. Salah satu solusi alternatif yang dapat diaplikasikan adalah dengan pemakaian fly ash sebagai material pengganti semen. Fly ash merupakan limbah hasil pembakaran batu bara Pembangkit Listrik Tenaga Uap (PLTU) serta dikategorikan sebagai limbah yang berbahaya (B3). Kandungan senyawa pozzolan berupa silika dan alumina yang cukup tinggi pada fly ash dapat dimanfaatkan sebagai bahan pengganti semen. Dari beberapa literatur yang ada, terdapat inovasi terhadap beton yaitu dengan mengkombinasikan beton SCC dengan pemakaian fly ash berkadar tinggi sebagai pengganti material semen atau yang dikenal High Volume Fly Ash-Self Compacting Concrete (HVFA-SCC).

Benda uji beton diuji dengan alat compressive testing machine (CTM). Beton yang menerima gaya tekan dari luar akan mengakibatkan adanya tegangan (stress) pada beton. Tegangan yang terjadi menimbulkan regangan (strain) pada beton. Data berupa tegangan dan regangan kemudian ditampilkan dalam kurva grafik tegangan-regangan. Dari data yang dihasilkan pada pengujian, kemudian dilakukan perhitungan secara empiris untuk mendapatkan nilai modulus elastisitas.

Penelitian ini mengkaji pengaruh dari penggunaan fly ash $50 \%$ terhadap kuat tekan beton dengan pengujian pembebanan uniaksial tekan umur 28 hari. 
Jurnal Matriks Teknik Sipil

DOI: https://doi.org/10.20961/mateksi.v8i3

ISSN: 2354-8630

E-ISSN: 2723-4223

Vol 8, No 3 (2020): September

\section{METODE PENELITIAN}

Penelitian ini dilakukan secara eksperimental, dimana pembuatan benda uji beton menggunakan fly ash dengan kadar 50\% dari total volume semen. Benda uji yang digunakan berbentuk silinder ukuran $150 \mathrm{~mm}$ x $300 \mathrm{~mm}$. Pengujian XRF dilakukan untuk mengetahui karakteristik fly ash, sedangkan untuk mengetahui karakteristik agregat yang digunakan dilakukan pengujian sesuai dengan standar SNI 03-2847-2013. Proses pengujian kuat desak beton menggunakan alat uji CTM (Compressive Testing Macbine). Dari pengujian benda uji tersebut didapat hasil kuat tekan maskimal dan karakteristik kurva tegangan-regangan beton HVFA-SCC pada umur 28 hari. Pengujian yang dilakukan untuk mengetahui karakteristik SCC mengacu pada standar EFNARC 2005 meliputi slump flow test, v-funnel test, dan l-box test.

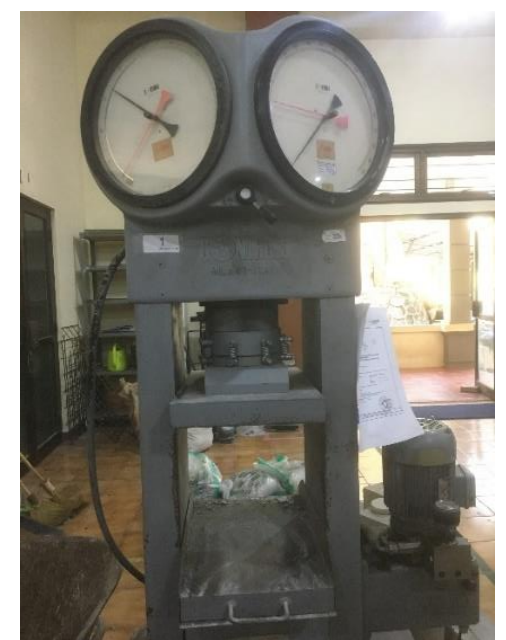

Gambar 1. Compressive Testing Machine

HVFA-SCC atau High Volume Fly Ash - Self Compacting Concrete merupakan sebuah inovasi dengan mengkombinasikan beton berjenis SCC dengan pemakaian fly ash kadar tinggi sebagai material pengganti sebagian semen. Syarat minimal kadar penggunaan fly ash pada beton HVFA adalah 50\% dari total semen (Shabina dkk., 2017). Kadar fly ash pada pembuatan HVFA-SCC ini adalah sebesar 50\%. Penggunaan fly ash dalam campuran beton diharapkan mampu meningkatkan kelecakan dan durabilitas beton.

Fly ash dibedakan menjadi 3 jenis, sesuai dengan pedoman ASTM C618-03 yang dapat dilihat pada Tabel 1.

Tabel 1. Kandungan senyawa kimia fly-ash

\begin{tabular}{lccc}
\hline \multicolumn{1}{c}{ Senyawa Kimia } & \multicolumn{3}{c}{ Kelas (\%) } \\
\cline { 2 - 4 } & $\mathbf{N}$ & $\mathbf{F}$ & $\mathbf{C}$ \\
\hline Oksida Silika $\left(\mathrm{SiO}_{2}\right)+$ Oksida Alumina $\left(\mathrm{Al}_{2} \mathrm{O}_{3}\right)+$ Oksida Besi & 70 & 70 & 50 \\
$\left(\mathrm{Fe}_{2} \mathrm{O}_{3}\right)$, minimum & & & \\
Trioksida Sulfur $\left(\mathrm{SO}_{3}\right)$, maksimum & 4 & 5 & 5 \\
Kadar air, maksimum & 3 & 3 & 3 \\
Kehilangan panas, maksimum & 10 & 6 & 6 \\
\hline
\end{tabular}

Kandungan senyawa kimia terbesar pada fly ash terdiri dari sillikon dioksida $\left(\mathrm{SiO}_{2}\right)$, alumunium oksida $\left(\mathrm{Al}_{2} \mathrm{O}_{3}\right)$, besi oksida $\left(\mathrm{Fe}_{2} \mathrm{O}_{3}\right)$, dan kalsium oksida $(\mathrm{CaO})$. Sebagian besar komposisi kimia fly ash tergantung berdasarkan jenis batu bara. Ukuran butiran fly ash yang sangat kecil dapat berfungsi sebagai filler yaitu fly ash akan mengisi ruang kosong pada campuran beton segar. Selain sebagai filler, fly ash juga berfungsi sebagai material substitusi semen. Kandungan silika $\left(\mathrm{SiO}_{2}\right)$ yang tinggi pada fly ash memberikan pengaruh pada proses hidrasi semen. Kandungan silika yang ada akan mengikat $\mathrm{Ca}(\mathrm{OH})_{2}$ kemudian membentuk senyawa C-S-H guna meningkatkan mutu beton (Solikin, 2012). 
Pengujian kuat tekan dilakukan menggunakan alat uji kuat tekan beton (Compressive Testing Machine). Selama uji kuat tekan, sampel silinder beton akan mendapatkan gaya tekan $(\mathrm{P})$ sehingga mengakibatkan terjadinya tegangan tekan (compressive stress).

Tegangan didefinisikan sebagai gaya per satuan luas penampang benda uji. Secara simbolis, tegangan dinotasikan dengan simbol " $\sigma$ " (sigma). Rumus untuk menghitung nilai tegangan ditampilkan pada persamaan [1]:

$\sigma=\frac{P}{A}$

keterangan:

$\sigma \quad=$ tegangan $(\mathrm{MPa})$

$\mathrm{P} \quad=$ gaya $(\mathrm{N})$

A = luas penampang benda uji $\left(\mathrm{mm}^{2}\right)$

Sampel beton silinder yang mendapatkan gaya tekan akan mengalami pemendekan pada arah aksial (regangan longitudinal). Regangan didefinisikan sebagai perubahan yang terjadi pada dimensi penampang benda uji dan dinotasi dengan simbol " $\varepsilon$ ". Rumus untuk menentukan nilai regangan disajikan pada persamaan [2]:

$\varepsilon=\frac{\Delta}{l_{0}}$

keterangan:

$\varepsilon \quad=$ regangan.

$\Delta l=$ selisih panjang awal dan panjang akhir benda uji (mm).

$l_{0} \quad=$ panjang awal benda uji (mm).

\section{HASIL DAN PEMBAHASAN}

Hasil Pengujian Fly Ash

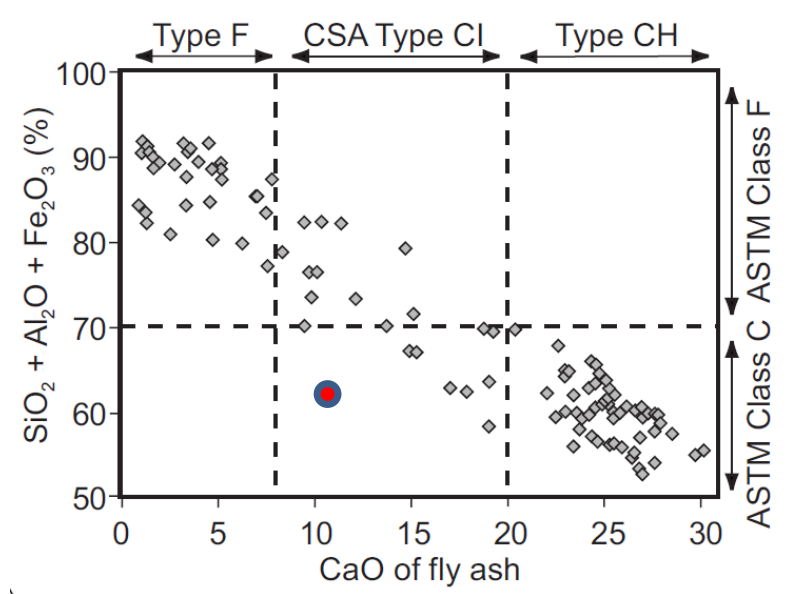

Gambar 2. Klasifikasi jenis fly ash

(sumber : ASTM C618-03)

Gambar grafik yang ditampikan pada Gambar 2, menujukkan bahwa jenis fly ash yang digunakan merupakan fly ash kelas C. 


\section{Pengujian Agregat Halus}

Tabel.2 Hasil pengujian agregat halus

\begin{tabular}{lccc}
\hline \multicolumn{1}{c}{ Pengujian } & Hasil & Standar & Keterangan \\
\hline Absorbtion & $3,093 \%$ & - & - \\
Apparent Specific Gravity & $2,594 \mathrm{gr} / \mathrm{cm}^{3}$ & - & - \\
Bulk Specific Gravity & $2,401 \mathrm{gr} / \mathrm{cm}^{3}$ & - & - \\
Kandungan Zat Organik & Kuning Muda & Kuning Muda & sesuai standar \\
Kandungan Lumpur & $0,5 \%$ & Maksimal $5 \%$ & sesuai standar \\
Bulk Specific SSD & $2,475 \mathrm{gr} / \mathrm{cm}^{3}$ & $2,4-2,6 \mathrm{gr} / \mathrm{cm}^{3}$ & sesuai standar \\
\hline
\end{tabular}

\section{Pengujian Agregat Kasar}

Tabel.3 Hasil pengujian agregat kasar

\begin{tabular}{lccc}
\hline \multicolumn{1}{c}{ Pengujian } & Hasil & Standar & Keterangan \\
\hline Absorbtion & $0,73 \%$ & - & - \\
Apparent Specific Gravity & $2,752 \mathrm{gr} / \mathrm{cm}^{3}$ & - & - \\
Bulk Specific Gravity & $2,698 \mathrm{gr} / \mathrm{cm}^{3}$ & - & - \\
Bulk Specific SSD & $2,7 \mathrm{gr} / \mathrm{cm}^{3}$ & $2,5-2,7 \mathrm{gr} / \mathrm{cm}^{3}$ & sesuai standar \\
Keausan Agregat & $26,92 \%$ & $<50 \%$ & sesuai standar \\
\hline
\end{tabular}

\section{Mix Design Beton (Rancang Campur)}

Formula bahan material pada pembuatan HVFA-SCC 50\% untuk $1 \mathrm{~m}^{3}$ ditampilkan pada Tabel 4.

Tabel 4. Mix design untuk $1 \mathrm{~m}^{3}$

\begin{tabular}{ccccccc}
\hline $\begin{array}{c}\text { Jenis } \\
\text { Beton }\end{array}$ & $\begin{array}{c}\text { Agregat } \\
\text { Kasar } \\
\left(\mathbf{k g} / \mathbf{m}^{3}\right)\end{array}$ & $\begin{array}{c}\text { Agregat } \\
\text { Halus } \\
\left(\mathbf{k g} / \mathbf{m}^{3}\right)\end{array}$ & $\begin{array}{c}\text { Semen } \\
\left(\mathbf{k g} / \mathbf{m}^{3}\right)\end{array}$ & $\begin{array}{c}\text { Fly Ash } \\
\left.\mathbf{( k g} / \mathbf{m}^{3}\right)\end{array}$ & $\begin{array}{c}\text { Air } \\
\left(\mathbf{l t} / \mathbf{m}^{3}\right)\end{array}$ & $\begin{array}{c}\text { Admixture } \\
\left(\mathbf{l t} / \mathbf{m}^{3}\right)\end{array}$ \\
\hline $\begin{array}{c}\text { HVFA- } \\
\text { SCC 50\% }\end{array}$ & 761,01 & 941,13 & 232,5 & 232,5 & 139,50 & 9,30 \\
\hline
\end{tabular}

\section{Pengujian Karakteristik SCC}

Pengujian pada beton segar guna mengetahui karakteristik SCC mengacu pada pedoman EFNARC 2005. "Specification and Guidelines for Self-Compacting Concrete".

Hasil dari pengujian beton segar ditampilkan dalam Tabel 5 - 7 .

Pengujian slump flow disajikan dalam Tabel 5.

Tabel 5. Slump flow test

\begin{tabular}{ccccc}
\hline Kode & $\mathbf{d}_{\mathbf{1}}(\mathbf{m m})$ & $\mathbf{d}_{\mathbf{2}} \mathbf{( \mathbf { m m } )}$ & $\mathbf{d}_{\text {rata-rata }}(\mathbf{m m})$ & $\mathbf{t}_{\mathbf{5 0}} \mathbf{( s )}$ \\
\hline HVFA- & 620 & 650 & 635 & 3 \\
SCC $50 \%$ & & & & \\
\hline
\end{tabular}

Pengujian L-Box test disajikan dalam Tabel 6.

Tabel 6. L-box test

\begin{tabular}{cccc}
\hline Kode & $\mathbf{h}_{\mathbf{1}}(\mathbf{m m})$ & $\mathbf{h}_{\mathbf{2}} \mathbf{( \mathbf { m m } )}$ & $\mathbf{h}_{\mathbf{2}} / \mathbf{h}_{\mathbf{1}}$ \\
\hline HVFA- & 90 & 90 & 1 \\
SCC $50 \%$ & & & \\
\hline
\end{tabular}


Jurnal Matriks Teknik Sipil

DOI: https://doi.org/10.20961/mateksi.v8i3

ISSN: $2354-8630$

E-ISSN: 2723-4223

Vol 8, No 3 (2020): September

Pengujian $V$ - funnel test disajikan dalam Tabel 7.

Tabel 7. V-funnel test

\begin{tabular}{cc}
\hline Kode & t (s) \\
\hline HVFA- & 6 \\
SCC $50 \%$ & \\
\hline
\end{tabular}

Data yang dihasilkan dari pengujian beton segar menunjukkan bahwa HVFA-SCC $50 \%$ memenuhi syarat sebagai beton SCC sesuai standar EFNARC 2005.

\section{Pengujian Kuat Desak Beton.}

Penguujian kuat desak beton dilaksanakan pada benda uji umur 28 hari dengan alat Compressive Testing Machine (CTM) untuk memperoleh nilai beban maksimum ( $\mathrm{P}_{\text {maks }}$ ) dan alat LVDT Indicator untuk memperoleh nilai perubahan panjang sampel beton. Hasil pengujian disajikan dalam Gambar 3 dan Tabel 8.

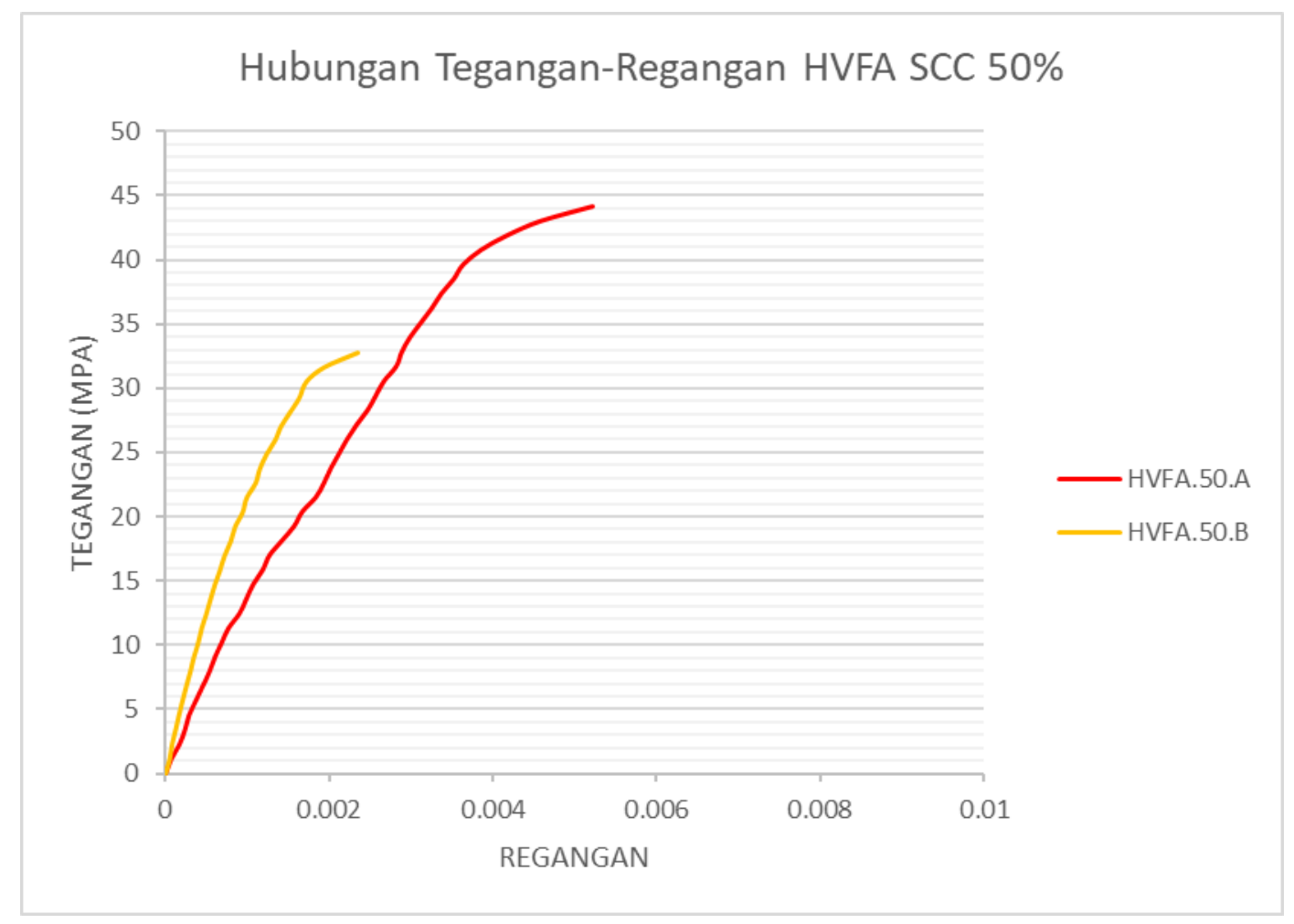

Gambar 3. Hubungan load-displacement HVFA-SCC 50\%

Tabel 8. Hasil kuat desak HVFA-SCC 50\%

\begin{tabular}{cccc}
\hline Benda Uji & $\begin{array}{c}\text { Luas } \\
\left(\mathbf{m m}^{2}\right)\end{array}$ & $\begin{array}{c}\text { Displacement } \\
(\mathbf{m m})\end{array}$ & $\begin{array}{c}\text { Beban Maks } \\
(\mathbf{N})\end{array}$ \\
\hline HVFA.50.A & 17671,46 & 1,5650 & 780000 \\
HVFA.50.B & 17671,46 & 0,7071 & 580000 \\
\hline
\end{tabular}

Berdasarkan nilai Load-Displacement, dapat dilakukan perhitungan untuk mendapatkan nilai kuat tekan maksimum dengan menggunakan rumus pada persamaan [1] dan [2]. Hasil perhitungan kuat tekan maksimum disajikan pada Tabel 9.

Tabel 9. Hasil perhitungan kuat tekan maksimum

\begin{tabular}{llll} 
Benda Uji & Luas $\left(\mathrm{mm}^{2}\right)$ & Beban Maks. & Kuat Tekan \\
\hline
\end{tabular}


Jurnal Matriks Teknik Sipil

DOI: https://doi.org/10.20961/mateksi.v8i3

ISSN: $2354-8630$

E-ISSN: 2723-4223

Vol 8, No 3 (2020): September

\begin{tabular}{cccc}
\hline & & $(\mathbf{N})$ & $(\mathbf{M P a})$ \\
\hline HVFA.50.A & 17671,46 & 780000 & 44,1390 \\
HVFA.50.B & 17671,46 & 580000 & 32,8213 \\
\hline
\end{tabular}

\section{KESIMPULAN}

Dari hasil pembahasan diatas dapat disimpulkan bahwa:

1. Nilai Load-Displacement maksimum kuat tekan beton HVFA - SCC Kadar 50\% disajikan seperti pada Tabel 8.

2. Pengguanaan fly ash sebesar 50\% menghasilkan kuat tekan maksimum beton HVFA-SCC yang disajikan seperti pada tabel 9.

3. Nilai kuat tekan yang dihasilkan pada setiap benda uji berbeda-beda dikarenakan perbedaan perilaku yang didapatkan pada setiap benda uji pada saat proses pembuatan beton.

\section{UCAPAN TERIMAKASIH}

Penulis menyampaikan ucapan terimakasih kepada dosen pembimbing yaitu Bapak Agus Setiya Budi S.T, M.T dan Bapak Dr. Senot Sangadji, S.T, M.T., yang telah memberikan pengarahan dan bimbingan dalam penelitian ini. Terimakasih juga kepada Tim Gabungan Penelitian HVFA-SCC 2020 yang telah membantu pelaksanaan penelitian ini.

\section{REFERENSI}

Anonym, 2013, " SNI 2847-2013 : Persyaratan Beton Struktural untuk Bangunan Gedung".

Anonym, 1997, "RILEM TC 148-SCC". "Test Methods For The Strain-Softening Response Concrete".

Anonym, 1991, "ASTM C618-03 : Standard Specification for Coal Fly Ash and Raw or Calcined Natural Pozzolan for Use in Concrete".

Anonym, 2005, " The European Guidelines for Self-Compacting Concrete : Specification and Guidelines for Self - Compacting Concrete", European Project Group.

Utami, S. A., Wibowo., Safitri, I, 2017, “Kajian Pengaruh Variasi Komposisi High Volume Fly Ash Terhadap Parameter Beton Memadat Mandiri dan Kuat Tekan Beton Mutu Tinggi”, Jurnal Matriks Teknik Sipil. Vol 5 No.4, pp. 1442-1448. 